\title{
The gas supply and gas inlet control systems of the fusion experiment Wendelstein 7-X
}

\author{
Jörg Schacht, Rudolf Brakel, Holger Viebke, Steffen Pingel, Andreas Wölk, Heike Laqua, Fred Schmidt, \\ Ina Müller, and the W7-X team
}

\begin{abstract}
After a detailed commissioning process the fusion experiment Wendelstein 7-X (W7-X) was ready to operate in December 2015. The gas supply system and the gas inlet system are two important technical systems of the W7-X device, offering a wide spectrum of functions for plasma vessel conditioning, and plasma operation as well as for diagnostic and calibration purposes.

A brief overview is given of the structure of both gas supply and gas inlet systems. The design of the control systems of the gas supply and the gas inlet are introduced and described. The application of the W7-X gas inlet system is explained during an experiment discharge.
\end{abstract}

Index Terms - Control and data acquisition, gas supply system, gas inlet system, piezo electrical valve, fast gas inlet

\section{INTRODUCTION}

$\mathrm{T}$ HE fusion experiment Wendelstein 7-X (W7-X) based on the stellarator concept is designed for continuous operation [1]. Its superconducting magnet system, which consists of 50 nonplanar and 20 planar coils, generates an optimized magnetic field. For the heating of the plasma three heating systems: ECRH (electron cyclotron resonance heating), NBI (neutral beam injection) and ICRH (ion cyclotron resonance heating) are foreseen. Especially, ECRH is capable of producing stationary heating power with high power. The important goal of the project $\mathrm{W} 7-\mathrm{X}$ is to examine the potential of an optimized stellarator for a nuclear fusion reactor. The first operational phase OP1.1 of W7-X was started on 10th of December 2015 after the commission phase was finished successfully. The first plasma discharges were made with Helium as operational gas. After a short learning phase with Helium plasma discharges the first plasma operation in Hydrogen took place at the beginning of February 2016. In the first operational phase OP1.1 of W7-X altogether 940 experiment programs were performed, which served for technical tests, conditioning of the plasma vessel, and for plasma-physical research. Besides Hydrogen and Helium other gases like Argon were used for physic's experiments.

Manuscript received June 11, 2017

J. Schacht, R. Brakel, H. Viebke, S. Pingel, A. Wölk, H. Laqua, I. Müller and F. Schmidt are with the Institute for Plasma Physics, Wendelsteinstraße 1, Greifswald, D-17491, telephone: +049(0)3834-882761, (e-mail: joerg.schacht@ipp.mpg.de).
Thus, storage and supply of different gas types are indispensable for preparation and processing of plasma discharges in fusion devices [2] [3] [4] [5]. The gas supply system and the gas inlet system are two independent technical systems of the W7-X device. The gas supply is mainly used for gas storage and gas supply purposes. The gas inlet system offers a wide spectrum of functions for plasma vessel conditioning, and plasma operation as well as for diagnostic and calibration purposes. In this contribution an overview about the gas supply systems of W7-X will be given. The structure of both gas supply and gas inlet systems will be explained. Furthermore, the design of the control systems of these systems are introduced and described. The application of the W7-X gas inlet system during an experiment discharge is explained. This contribution concludes with a status and outlook for the operational phase OP1.2a.

A short outlook for the preparation of the gas systems for the next operational phase OP1.2 of W7-X will be given.

This contribution ends with a short summary.

\section{OVERVIEW SYSTEM ARCHITECTURE GAS SUPPLY SYSTEMS}

For preparation and operation of a fusion experiment the supply of gases is a basic requirement. Many main and auxiliary systems of W7-X have to be supplied with different gas species.

The utilized gas species of the gas supply system are separated into two different groups: the gas species for operation (operational gases) and gas species for conditioning purposes (conditioning gases). Table 1 gives an overview about the gas species for different application at W7-X.

A System Modeling Language (SysML) block definition diagram (BDD) of the entire gas system of W7-X is shown in Fig. 1. This BDD shows the general structure of the gas system in a black box view. The gas system consists of four blocks: 1. gas supply systems, 2 . gas consumer systems, 3. gas exhaust systems, and 4. physical environment. 


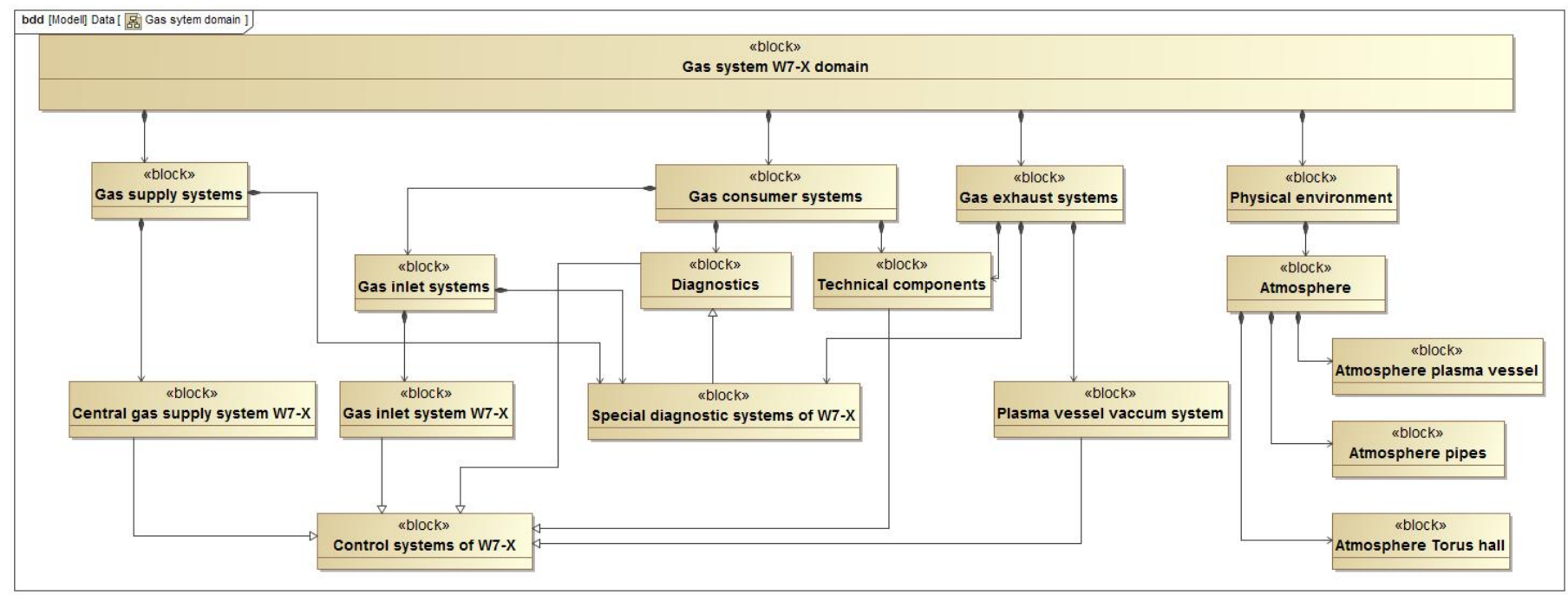

Fig. 1 SysML block definition diagram of gas systems of W7-X

TABLE I. GAS SPECIES OF W7-X GAS SUPPLY SYSTEM

\begin{tabular}{|c|c|c|c|}
\hline $\begin{array}{l}\text { Main } \\
\text { group }\end{array}$ & Sub group & $\begin{array}{l}\text { Gas } \\
\text { species }\end{array}$ & Application \\
\hline \multirow[t]{3}{*}{$\begin{array}{l}\text { operational } \\
\text { gas species }\end{array}$} & $\begin{array}{l}\text { primary } \\
\text { working } \\
\text { gases }\end{array}$ & $\begin{array}{l}\text { Hydrogen, } \\
\text { Deuterium, } \\
\text { Helium, }\end{array}$ & $\begin{array}{l}\text { plasma } \\
\text { operation }\end{array}$ \\
\hline & $\begin{array}{l}\text { secondary } \\
\text { working } \\
\text { gases }\end{array}$ & $\begin{array}{l}\text { Neon, } \\
\text { Argon, } \\
\text { Nitrogen, }\end{array}$ & $\begin{array}{l}\text { for a controlled } \\
\text { injection of } \\
\text { impurities in } \\
\text { the plasma edge }\end{array}$ \\
\hline & $\begin{array}{l}\text { diagnostic } \\
\text { gases }\end{array}$ & $\begin{array}{l}\text { Hydrogen, } \\
\text { Deuterium, } \\
\text { inert } \\
\text { gases, } \\
\text { Nitrogen } \\
\end{array}$ & $\begin{array}{l}\text { for injection } \\
\text { into the plasma } \\
\text { for diagnostic } \\
\text { purposes }\end{array}$ \\
\hline \multirow[t]{3}{*}{$\begin{array}{l}\text { gases for } \\
\text { special } \\
\text { purposes }\end{array}$} & $\begin{array}{l}\text { conditioning } \\
\text { gases }\end{array}$ & $\begin{array}{l}\text { Hydrogen, } \\
\text { Deuterium, } \\
\text { Helium, }\end{array}$ & $\begin{array}{l}\text { gases for } \\
\text { discharges for a } \\
\text { conditioning of } \\
\text { the plasma } \\
\text { vessel wall }\end{array}$ \\
\hline & $\begin{array}{l}\text { coating } \\
\text { gases }\end{array}$ & $\begin{array}{l}\text { Diborane, } \\
\text { Silane, } \\
\text { Methane, }\end{array}$ & $\begin{array}{l}\text { gases for a } \\
\text { coating of the } \\
\text { plasma vessel } \\
\text { wall }\end{array}$ \\
\hline & $\begin{array}{l}\text { gas for } \\
\text { cryopumps }\end{array}$ & Argon & $\begin{array}{l}\text { preparation of } \\
\text { cryopumps } \\
\text { (Argon frosting) }\end{array}$ \\
\hline
\end{tabular}

The blocks 1-3 represents the technical systems for gas supply, gas inlet systems, and exhaust systems for disposal of gases. The block physical environment summarizes all relevant environmental conditions inside the plasma vessel, in gas tubes and in the torus hall of W7-X, having an influence on the systems of blocks 1-3.

Gas supply systems are the technical component gas supply system W7-X and special diagnostic systems of W7-X with an integrated gas supply. Gas consumer systems need gas for their operations. Systems, which realize an inlet of gases into the plasma vessel of experiment $\mathrm{W} 7-\mathrm{X}$ are the component gas inlet system W7-X, the pellet injector and special diagnostic systems. Some technical components need gas for cooling tasks, for operation of pump stands (dilution of explosive exhaust gases), and for the generation of pressure conditions inside water cooling circuits.

A brief overview of both, gas supply system and gas inlet system of W7-X is given in the next sections.

\section{A. Overview central gas supply system}

The central gas supply system (cGSS) is the major gas supply system at W7-X. Also laboratory experiments and infrastructure components (e.g. Nitrogen gas supply for water cooling system) are consumer of gases of cGSS.

The main task of cGSS is a controlled supply of the gases hydrogen, deuterium, helium, nitrogen, methane, rare gases, and mixtures thereof. In addition diborane mixtures can be provided for coating of the inner wall of the plasma vessel.

The gas inlet for experiment operation of W7-X is not a task of cGSS. Therefore its control system is not integrated into the plasma experiment control system of W7-X.

Table 1 gives an overview of the necessary gas species for W7-X operation for the different applications.

Fig. 2 shows the structure of cGSS. This system serves as a gas storage and gas provider for diagnostics and for technical components. In addition gas mixtures can be produced on demand by using the gas mixer device.

The interface between cGSS and the gas inlet system is the valve manifold inside the torus hall of $\mathrm{W} 7-\mathrm{X}$. The valve manifold switches the gas supply lines with different gas species to the ring line system (ring line RL1-RL4). The ring line for coating gases and the ring line for Nitrogen are directly connected with gas lines of the cGSS.

Due to processing of explosive and poisonous gas species the requirements for a safe operation regarding the personnel and machine as well as for explosion prevention and protection were very important for the design and implementation of the gas system. 


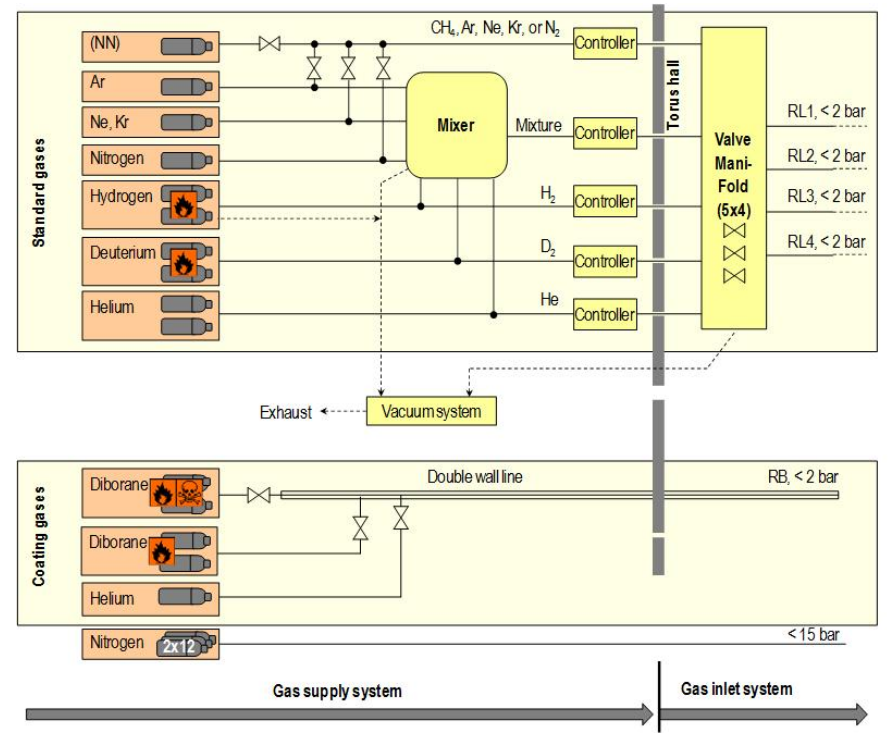

Fig. 2 Structure of central gas supply system (cGSS) of W7-X

The control system of cGSS is based on a Programmable Logic Device (PLC) control system Siemens Simatic S7-400 and a supervision system Siemens WinCC. All safety instrumented functions are implemented in a configurable control system of type "PNOZ multi" (Company Pilz / Germany). The PLC control system allows controlling all valves, pumps and mass flow controllers individually. In addition, automatic functions are implemented for a large number of complex process sequences.

Actual values and status information are transmitted via Ethernet to the central Operational Management (cOPM) of the central control system of W7-X. All consumers of gases receive information related to cGSS via data packets from cOPM. Control interactions between gas consumer components and cGSS are not implemented. A safety signal interface connects the central Safety System (cSS) of W7-X with the local Safety System (ISS) of cGSS control system. The cSS sends emergency stop and enable signals for dedicated activities with a hazard potential to the ISS of gas supply system. The components confirm that they are in the state emergency stop or in a safe state, respectively.

All important set values, actual values and status information are stored in the PLC short time data archive and into the long time data archive of W7-X.

\section{B. Overview gas inlet system}

The main task of the gas inlet system is to control gas inlet into the plasma vessel for plasma experiment operation and for conditioning of the plasma vessel (e.g. boronization and glow discharges). Thus the gas inlet system is integrated in the operational management and in the plasma experiment control system of W7-X.

The gas inlet system of W7-X permits a fast switch of the gas species for every inlet position of W7-X plasma vessel for operational gases and for a change of the gas species of the supplying ring lines can be achieved within an adequate time period.

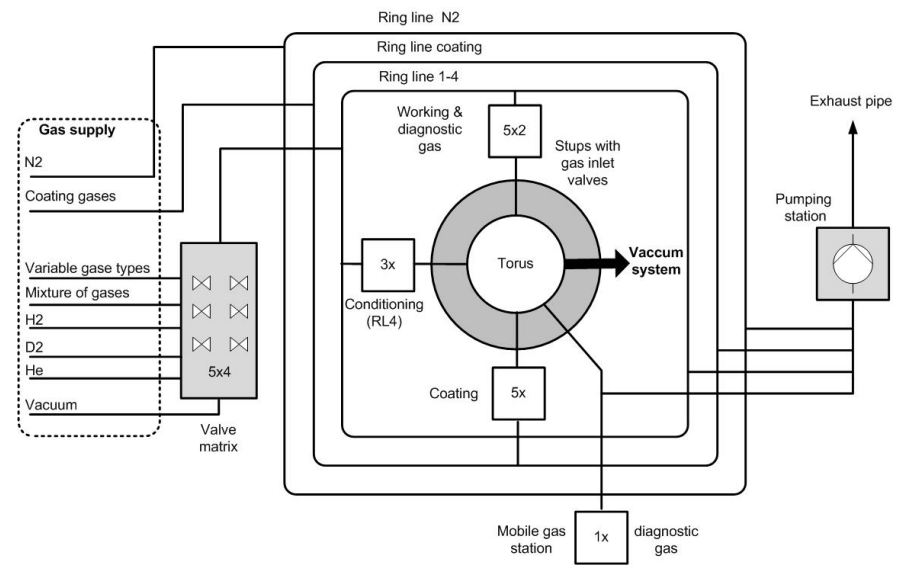

Fig. 3 Structure gas inlet system of W7-X

Fig. 3 gives an overview about the structure of the W7-X gas inlet system including the connection to the gas supply system and the exhaust system.

The supply of gases into the plasma vessel takes place via dedicated ports. The machine W7-X has altogether 18 ports, dedicated to gas inlet purposes: 3 ports for conditioning, 10 ports for inlet of operational gases, and 5 ports for coating. A mobile gas station can be used as an additional gas supply of special gases for diagnostic purposes.

A system of ring lines is installed around the W7-X machine in the torus hall and allows an easy connection of different gas inlet positions with the gas tubes of the ring lines. The gas station of the central gas supply system for the gas sort Nitrogen is directly connected with the ring line "RL $\mathrm{N}_{2}$ " and is available for the consumers of Nitrogen.

A pump station allows an evacuation of all ring lines, which is necessary e.g. for a change of the gas species in a ring line.

Table 2 summarizes the functions of the different gas ring lines.

TABLE II. FUNCTIONS OF THE GAS LINES OF GAS INLET SYSTEM

\begin{tabular}{ll}
\hline Gas line & Function \\
\hline$R L 1$ & plasma discharge fueling $1(\mathrm{H} 2, \mathrm{D} 2, \mathrm{He})$ \\
$R L 2$ & plasma discharge fueling $2(\mathrm{H} 2, \mathrm{D} 2, \mathrm{He})$ \\
RL3 & impurity seeding $(\mathrm{N} 2, \mathrm{Ne}, \mathrm{Ar}, \mathrm{..})$, Ar-frosting \\
$R L 4$ & wall conditioning $(\mathrm{He}, \ldots)$ \\
$R L N$ & 1.1 bar nitrogen for technical applications \\
\hline
\end{tabular}

The connection between the ring lines and the gate valves of the plasma vessel of $\mathrm{W} 7-\mathrm{X}$ is realized via so called gas modules. Fig. 4 shows the different designs of gas modules for gas inlet of operational gases (Fig.4a) and for conditioning and coating gases (Fig. $4 b$ ).

For the gas inlet of operational gases a fast response time of the gas inlet valves in a range of $\mathrm{t}<2 \mathrm{~ms}$ is required. The gas flow must be in a range of $\mathrm{q}=1-200 \mathrm{mbar} 1 \mathrm{~s}^{-1}$. A stable and a calibrated measurement of the gas flow through the valves are required for density and radiation control of plasmas as well as to compute particle balances. 

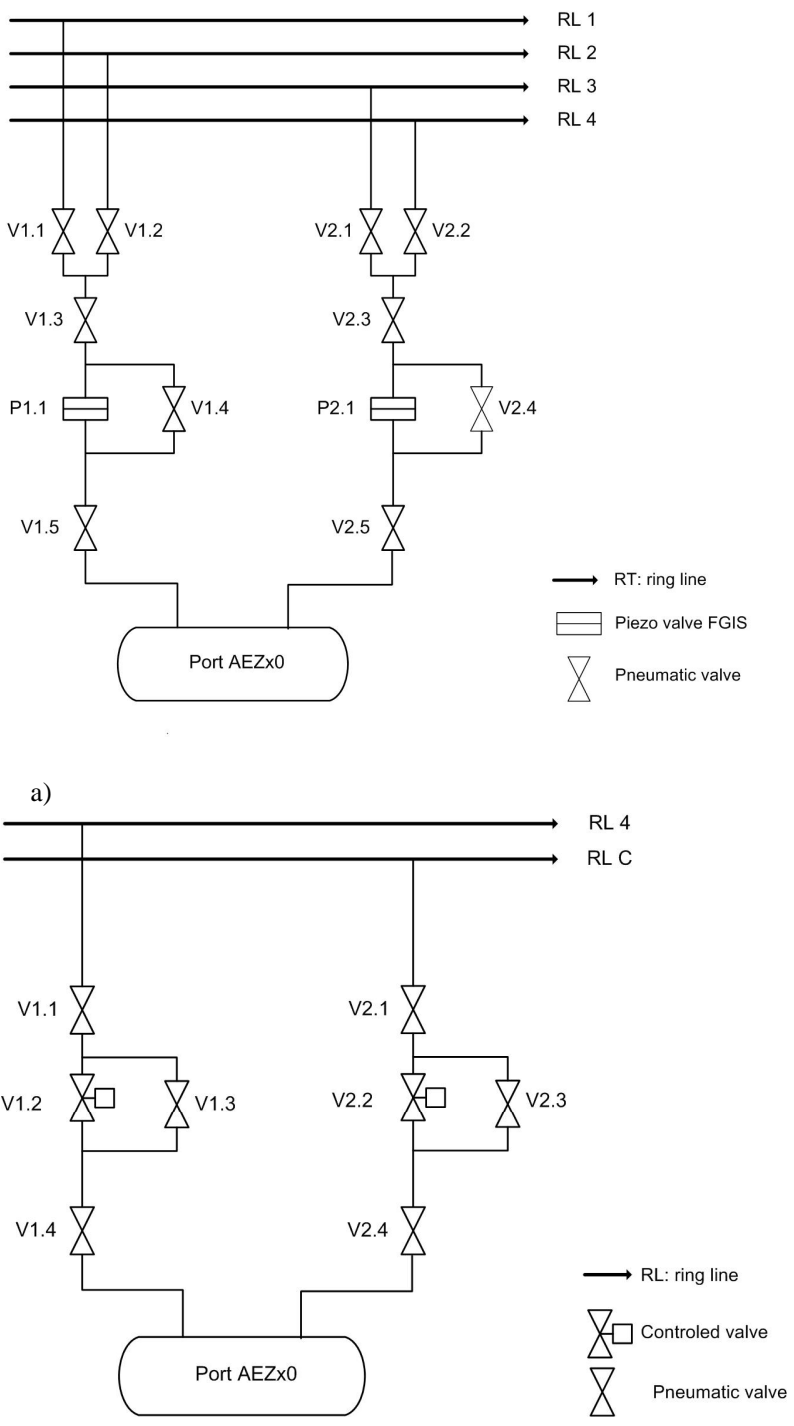

b)

Fig. 4 Gas inlet module for operational gases (a) and for conditioning and coating gases $(b)$

Therefore, 11 fast gas inlet piezo valves PA10 [3, 6] with integrated pressure transducers are used for a fast gas inlet into the plasma vessel (see Fig. 5).

Every piezo-electric valve is directly connected to a valve driver board [7]. The fast control station (FCS), an industrial computer running with a real time operating system (VxWorks, Fa. Wind River), controls all connected 11 valve units via analogue control signals. The FCS is equipped with software modules for different purposes, e.g. modules for processing the experiment program definitions, modules for the communication with internal and external control components, and also with modules for signal processing and controlling.

A PLC is responsible for all tasks of the operational management and for all slow real time measurements and control tasks of the component gas inlet. Furthermore, the PLC provides human machine interface (HMI) for supervision and visualization, realized with the application program WinCC, Fa. Siemens.

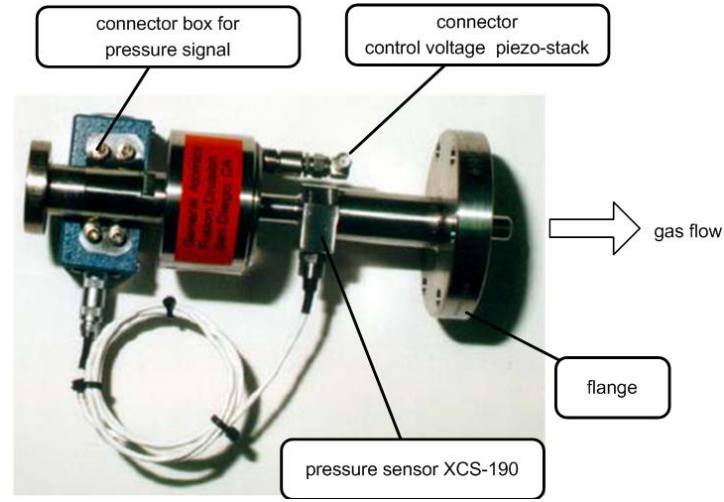

Fig. 5 Piezo valve PA10 for fast gas inlet

The control system of gas inlet system is designed for processing of operational functions related to experiment preparation (e.g. glow discharge, boronization) as well as for fast gas inlet tasks during segment program controlled plasma discharges [8] [9] [10].

TABLE III. SERVICES OF GAS INLET CONTROL SYSTEM

\begin{tabular}{ll}
\hline Service type & Service functions \\
\hline $\begin{array}{l}\text { Supervision } \\
\text { and }\end{array}$ & Visualization and selection of operational states \\
visualization & controller, gate valves of plasma vessel, \\
& Visualization of status of safety signals and \\
& safety functions, \\
& Visualization of messages, e.g. alarms and \\
& warnings and process messages, \\
& Visualization of an pipe \& instrumentation \\
& scheme,
\end{tabular}

Control Control of operational states of the component and of controllable devices (e.g. mass flow controller, valves),

Realization of safety instrumented function of the local safety system (e.g. reaction on emergency stop, control of safety relevant activities), Control of valves, plasma vessel gate valves, piezo valves, and mass flow controller manually by operator or automatically by segment program operation or by central operational management for processing of operational functions (e.g. glow discharge, boronization), Control functions for control groups of valves: open/close function for operator interaction

Data Measurement of actual values of sensors: acquisition temperatures, gasflows, pressures, position indicators, alarm and warnings of gas warning system,

Data storage into long term (central W7-X data archive) and short term data archive (local data archive of PLC data): actual values, set values messages,

Table 3 gives an overview about the main services of the gas inlet control system.

The definition of set values for the Piezo valves of the fast gas injections is based on four control groups for these valves. The operator configures the control groups via the Human Machine Interface (HMI) of the PLC. The 11 piezo valves 
have to be assigned into 1 up to 4 control groups for the fast gas inlet during experiment program runs. Every control group is dedicated to a special gas inlet task during experiment runs. Table 4 describes the tasks of the control groups 1-4.

Fast control functions for gas inlet operation during plasma experiments are realized by a fast control station (FCS) equipped with special control software for feed-forward and feed-back operation of piezo valves.

\section{TABLE IV. CONTROL GROUPS OF PIEZO VALVES}

\begin{tabular}{lll}
\hline Control group & Task & Gas type \\
\hline Control group 1 & $\begin{array}{l}\text { Feed-forward control gas } \\
\text { inlet }\end{array}$ & Operational gas \\
Control group 2 & $\begin{array}{l}\text { Feed-back control gas inlet } \\
\text { for plasma density control }\end{array}$ & Operational gas \\
Control group 3 & $\begin{array}{l}\text { Feed-forward control gas } \\
\text { inlet }\end{array}$ & Impurity gas \\
Control group 4 & $\begin{array}{l}\text { Feed-back control gas inlet } \\
\text { for plasma radiation } \\
\text { control }\end{array}$ & Impurity gas \\
& & \\
\hline
\end{tabular}

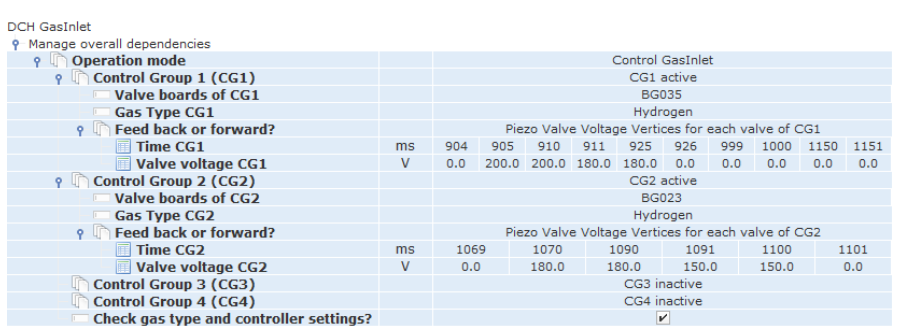

Fig. 6 Segment program description for 4 control groups of fast gas inlet

This controller is also a part of the segment control system of W7-X, which is responsible for processing of the predefined sequences of control commands of the experiment program for the gas inlet system. The experiment program entries for the gas inlet system defines the control modes for the Piezo valves (feed-back, feed-forward), set values, configuration parameters for the gas control algorithm and the source of set values. For the density control of the plasma the plasma density value of the diagnostic "interferometry" is used as a set value for a plasma density controller. The density value is send periodically via a data network based on Ethernet layer 2 protocol. The control cycle time for setting new set values for gas inlet is $t_{\text {cycle }} \leq 1 \mathrm{~ms}$.

An example of a plasma experiment program (so called "segment program") definition for the control groups of fast gas inlet is shown as a screen shot of the editor mask of the W7-X experiment program editor tool Xedit [11] in Fig. 6.

Following parameters of the fast gas injection system are set:

- Member of control group 1 is piezo valve gas inlet module BG035; member of control group 2 is piezo valve gas inlet module BG023.

- Control mode is feed forward for control group 1 and 2.

- Control group 3 and 4 are inactive,

- Gas type for control group 1 and 2 is Hydrogen.

- The gas flow reference through the Piezo valves is defined as vertices of control voltages over time.

\section{COMMISSIONING AND OPERATION FOR OP1.1}

The cGSS of W7-X was in operation since 2004. A commissioning for the first operational phase OP1.1 of W7-X was not necessary for this reason.

The gas inlet system was commissioned in September 2015. All Piezo valves were tested and calibrated with Helium at a vacuum tank in the lab (see Fig. 7).

The mass dependence of the gas flow regarding the gas species was checked with Argon. An integrated test of the gas inlet system by using the plasma control system [10] was performed by injecting Helium into the pumped plasma vessel of W7-X.

The cGSS and the gas inlet system worked very reliable during operational phase OP1.1 of W7-X. Fig. 8 shows a signal plot of a plasma experiment with one gas prefill (Hydrogen) via piezo valve BG023: Control Group 1 and two gas fill sections (Hydrogen) via BG035: Control Group 2) during the plasma phase.

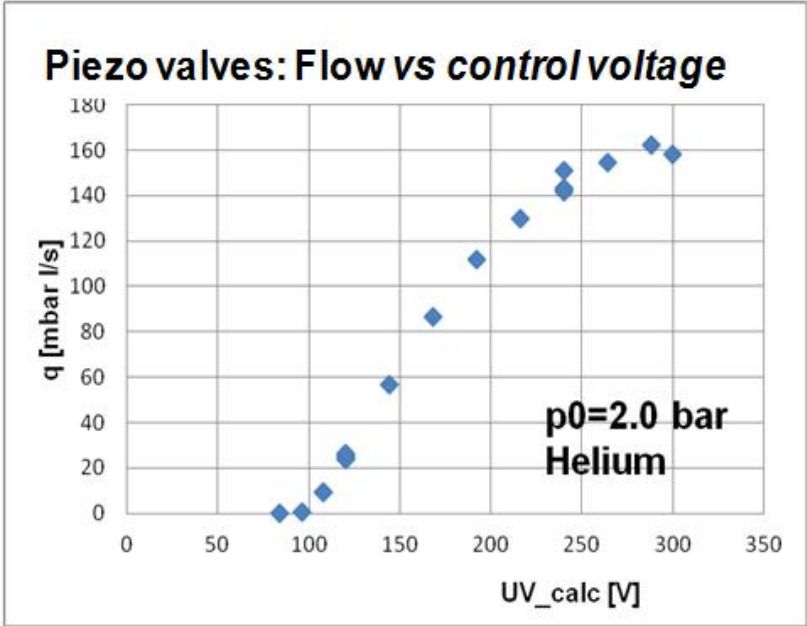

Fig. 7 Calibration curve piezo valve\#1: Gas flow vs. control voltage

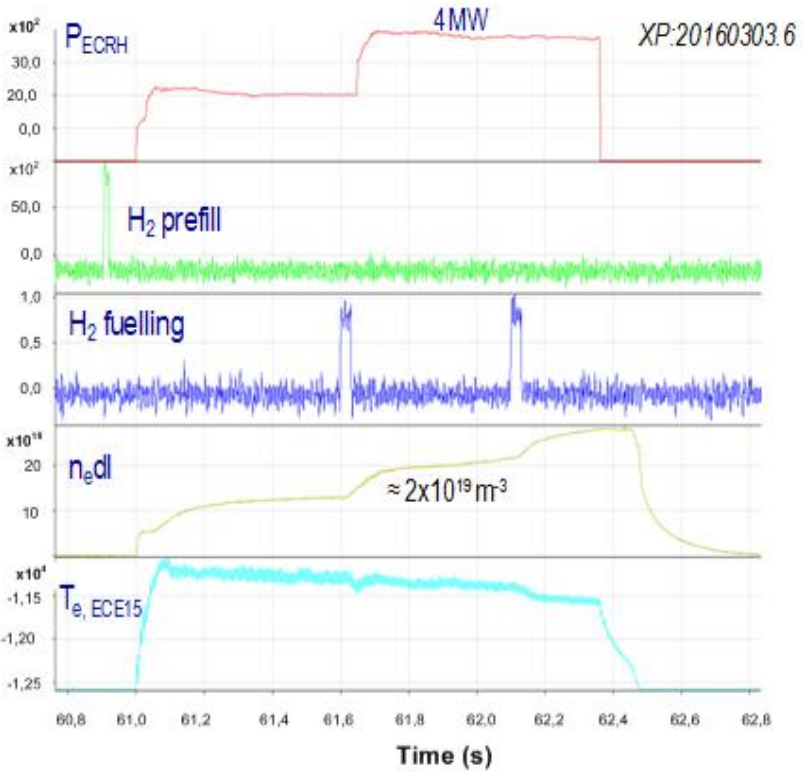

Fig. 8 Signal plot (ECRH heating power, H2 gas flow BG036, H2 gas flow BG042, plasma density, ECE: electron temperature) of W7-X plasma experiment ID: XP20160303.6 


\section{OUTLOOK}

The next upcoming operational phase of W7-X (OP1.2a) will start in August 2017. In examination of the experiences of glow discharge operations in OP1.1the mass flow controllers (MFC) for gas inlet for conditioning gases were replaced with MFC with higher flow rate (2000 instead of $500 \mathrm{sccm}$ ).

The PLC program of the gas supply system has been extended with new complex control functions for operating, e.g. the evacuation of sections of gas tubes and complete ring lines. In OP1.2a the coating of the plasma vessel by boronization with diborane will be operable. All necessary modifications of gas supply, gas inlet and safety system for boronization are ready. The integral commissioning will be performed in July 2017.

The commissioning phase for OP1.2a of W7-X including the commissioning of cGSS and gas inlet system is ongoing. The start of the plasma experiment campaign of OP1.2a is planned end of August 2017.

\section{SUMMARY}

The fusion experiment W7-X has successfully accomplished the commissioning and the first operational phase OP1.1. The whole gas system of W7-X worked reliably with high availability during OP1.1. The control functions for operational management tasks and for experiment operations fulfills the specified requirements.

In preparation of operational phase OP1.2a the control systems of both gas systems will be prepared for coating process function of plasma vessel.

\section{REFERENCES}

[1] H.-S. Bosch, R. Brakel, M. Gasparotto et al., "Transition from Construction to Operation Phase of the Wendelstein 7-X Stellarator", IEEE Trans. on Plasma Science., vol. 42, no. 6, pp. 432-438, Feb. 2014.

[2] T. Härtl, V. Rohde, V. Mertens, \& ASDEX Upgrade Team, "Status and perspectives of the ASDEX Upgrade gas inlet system", Fusion Engineering and Design, 96-97, 265-268. doi:10.1016/j.fusengdes.2015.06.166.

[3] S. Bates, K. H. Burell et al., "Fast gas injection system for plasma physics experiments", Review of scientific instruments 55(6):934-939, July 1984 ,

[4] Y. O. Kim, J. I. Song, K. P. Kim, et al., Control and operation of the gas injection system for KSTAR tokamak, Fusion engineering and design, Volume 88, Issues 6-8:1132-1136, October 2013.

[5] G. Bonizzoni, F. Gnesotto, P. Sonato, et al., "The vacuum and gas inlet system for the RFX", Vacuum, Volume 41, Numbers 4-6:1503-1507, 1990.

[6] Fast gas injection system, General Atomics and affiliated companies, http://www.ga.com/fast-gas-injection-system, 2001 (accessed 6 February 2018).

[7] J. Schacht, J. Sachtleben, H. Jensen et al., „Piezo valve controller for the gas inlet system of fusion experiment Wendelstein 7-X,“, Fusion engineering and design 87(2012) 1961-1966.

[8] Werner, T. Bluhm, M. Grahl, J. Schacht et al., "Cutting edge concepts for control and data acquisition for Wendelstein 7-X", IEEE 25th Symposium on Fusion Energie (SOFE), 2013,

[9] H. Laqua, H. Niedermeyer, and J. Schacht, Control system of WENDELSTEIN 7-X experiment, Fusion Engineering and Design 6668 (2003) 669-673.
[10] J. Schacht, H. Niedermeyer, H. Laqua, et al., Tasks and structure of the WENDELSTEIN 7-X control system, Fusion Engineering and Design 66-68 (2006) 1799-1806.

[11] Spring, M. Lewerentz, T. Bluhm, et al., "A W7-X experiment program editor- A usage driven development", Fusion engineering and design, Volume 87, Issues 12:1954-1957, December 2012. 